\title{
AS INSTITUIÇÕES DE PESQUISA INDEPENDENTES E A QUESTÃO DEMOCRÁTICA*
}

José Arthur Giannotti e Gabriel Cohn

Tullo Vigevani: Não se trata aqui de um grande debate sobre temas gerais ou intelectuais ou sobre a política contemporânea, mas de uma discussão sobre as instituições de pesquisa independentes e a luta pela democracia no Brasil. A idéia de convidar o professor [José Arthur] Giannotti obviamente é muito fácil de entender pelo papel que ele teve na construção e no desenvolvimento do Cebrap; o prof. Gabriel Cohn, exatamente pela razão paralela a essa: pelo papel que desempenhou no período de fundação e que vem desempenhando até hoje no desenvolvimento do Cedec. Trata-se de uma reflexão necessária porque, olhando do ponto de vista do Cedec, temos problemas de identidade, de crise, de perspectivas. Quando essas instituições foram criadas - o Cebrap, em 1969, e o Cedec (que está comemorando agora 30 anos) em 1976 -, atravessava-se um período da história brasileira extremamente diferente do atual, quando se

\footnotetext{
* Seminário realizado no Cedec, 26.05.2006.
} 
modificou a institucionalidade da vida intelectual e também da vida política brasileira - profundamente desde 1969, mas diria que profundamente desde 1976 também. Trata-se aqui então de conhecer a experiência, a avaliação e o papel intelectual dessas instituições naquele contexto. Antes de passar a palavra aos nossos convidados, chamo a professora Amélia Cohn que, como ex-presidente da entidade e como nossa decana, fará um pequeno depoimento sobre o Cedec.

Amélia Cohn: Trinta anos depois, já balzaquiano, o Cedec retoma na sua comemoração o tema que nunca o abandonou - a questão da democracia - que não só constituiu a principal razão de sua criação, como durante todo esse período foi a questão substantiva que vem justificando sua existência enquanto um centro de debate, pesquisa e ação.

Ao comemorar seus 20 anos de existência, o tema do nosso conclave foi "Brasil, brasis - desenvolvimento e inclusão social"; nos 25 anos, "Pensar o Brasil - por que pensar; como se pensa; como pensar?”; e nestes 30 anos, o tema é "Democracia, desenvolvimento e políticas públicas”. Como se vê, em termos dos eixos centrais que norteiam as atividades do Cedec, democracia, desenvolvimento e inclusão social - nas suas várias vertentes, inclusive a dos direitos humanos - não são jamais abandonados; tampouco outro eixo, próprio de sua personalidade institucional: seu traço de associar a produção científica e acadêmica (vínculo de origem de todos nós) ao diálogo imediato com os processos e as dinâmicas políticas e sociais contemporâneas. Distinguindo sempre, no entanto, o momento da produção do conhecimento daquele da intervenção na realidade. 
Da minha trajetória profissional destaco o orgulho de ter participado da história do Cedec desses trinta anos, dez dos quais presidindo a instituição, contando para tanto com a temerária confiança dos colegas, o que muito me honra; mas diga-se também que o exercício dessa estafante tarefa durante período tão longo não se deveu exatamente à minha querência, mas à sábia resistência dos colegas em assumir o posto.

Nessa longa e proveitosa trajetória, em que o Cedec foi construindo parcerias com outras instituições similares e quebrando as resistências das universidades à nossa dupla militância, o que sempre caracterizou nossa produção foi, com apoios de financiamentos de agências internacionais, e algumas instituições nacionais de fomento à pesquisa, uma valiosa característica que nos é muito cara, e que tem a ver com a predominância do traço crítico na busca da compreensão dos fenômenos e processos sociais: a capacidade de captarmos problemas e questões emergentes a partir de fenômenos e processos sociais "novos", quando ainda em estágios embrionários de institucionalização. Foi assim com a questão dos movimentos sociais, do novo sindicalismo, dos direitos humanos, dos bóias frias, dos meninos de rua, da saúde como direito e como consumo, dos acidentes de trabalho como uma forma de violência, e mais recentemente, a consolidação da área de relações internacionais.

Mais que isso, da minha perspectiva particular, foi a possibilidade de, a partir da credibilidade institucional do Cedec como centro de produção de um conhecimento "crítico porém responsável”, poder deste lugar contribuir com dois governos de forças políticas distintas, exatamente com a bagagem que acumulei a partir das pesquisas aqui desenvolvidas 
com as equipes que fui formando, montando e que foram se desmontando ao longo do tempo, como é natural. Refiro-me aqui à experiência de ter sido a relatora-geral, e nessa condição a autora, do Relatório Nacional para a Cúpula do Desenvolvimento Social de Copenhague, em 1995, bem como à experiência de ter participado da formulação e implantação, no primeiro governo Lula, do Programa Bolsa Família.

No entanto os tempos mudaram. Avanços na democracia formal convivem com brutais violências e retrocessos das ações repressivas do Estado; avanços na área social, e nos indicadores sociais, convivem com a permanência de brutais índices de desigualdade social; e não bastasse isso, no âmbito da produção científica e da vida acadêmica, prevalecem hoje em dia parâmetros métricos de avaliação que vão de encontro com o "espírito" de instituições como o Cedec, e que sempre lhe deu vida e vigor. Com isso o que estou querendo dizer é que o Cedec, nesses trinta anos, só foi o que foi, e do que muito todos nos orgulhamos, porque:

1. contou com a possibilidade de ter quadros dirigentes e de coordenação de pesquisa que se dedicaram quase que exclusivamente à instituição, hoje condição não conveniente ou mesmo impossível para quem se responsabiliza por ela e tem a dupla militância - na universidade e em instituições de pesquisa como a nossa.

2. contou com financiamentos institucionais que favoreceram a possibilidade do desenvolvimento de pesquisas em fina sintonia com os processos sociais em curso, respondendo muito mais aos desafios e às demandas colocadas pela própria realidade social do que a aqueles pautados pelo debate estritamente acadêmico. 
Com isso, o Cedec pôde manter sua independência e autonomia na definição de suas pautas e agendas de pesquisa, que sempre foram formuladas "a contrapelo" do instituído, do já consagrado (e que no meio acadêmico, então ainda não pautado pelo produtivismo, era valorizado). Assim, a meu ver a grande indagação que fica na comemoração desses nossos trinta anos é se, a partir das novas regras vigentes no meio acadêmico, dos novos padrões de financiamento das instituições e agências nacionais e internacionais e do tipo de demanda que governos locais, estaduais e federal fazem às instituições como a nossa e nossos pares, e que já vêm pautados, é possível continuar nessa trajetória que sempre deu vida ao Cedec, e vem sendo sua razão de ser. Penso que por ser este um tema para nós vital, é que temos hoje aqui José Arthur Giannotti e Gabriel Cohn para falarem a respeito.

José Arthur Giannotti: Creio que precisamos começar refletindo desde logo sobre a dupla face das nossas instituições. De um lado, estamos ligados à universidade, de outro lado, ao Cebrap, ao Cedec e assim por diante; somos instituições autônomas. Não se pode esquecer a questão salarial: a maioria de nós complementa os baixos salários das universidades com o que ganha nessas instituições; mas a questão é mais profunda e podemos percebê-la analisando um pouco de nossas histórias.

Em primeiro lugar, é preciso lembrar o formato da Universidade de São Paulo. A USP se organizava por um sistema de cátedra, perverso, mas muito interessante: o professor catedrático era absoluto, os assistentes eram nomeados ou demitidos ad nutum, o que criava uma situação muito engraçada, porque o professor cretino obviamente escolhia assistentes cretinos 
e o trabalho emperrava; mas o professor genial conseguia desenvolver docência e pesquisa de alto nível. Num universo pantanoso, o bom catedrático montava seu grupo, que alocava numa universidade multifacetada. Quero lembrar o caso de Samuel Pessoa que, na década de 1950, formou um Departamento de Parasitologia de altíssimo nível. A ciumeira interna ajudou Adhemar de Barros, em nome da Revolução de 1964, a demitir todo mundo. Muitos desses professores fizeram grandes carreiras no exterior, poucos conseguindo voltar depois da anistia, uma vez que não encontravam na Universidade nem cargos nem condições de pesquisa equiparáveis aos que já tinham conseguido. Cada boa cátedra era quase um instituto interno, o que livrava os professores da luta ideológica e da burocracia universitária.

Então, começou o combate para a reforma da universidade, da qual participamos intensamente. O modelo era aquele da Universidade de Brasília, organizada em departamentos. Neles, professores e investigadores tornaram-se iguais no que concerne aos trabalhos da pesquisa e da docência. Mas essa dispersão acabou afetando o ensino, que deixou de ter uma estrutura coletiva, com uma divisão racional de trabalho. Lembro-me perfeitamente de que, quando voltei à USP em 1982, depois da anistia, quis dar um curso de $1 .^{\circ}$ ano, deixando claro que só o faria se tivesse auxiliares. Era evidente que, naquele momento, em plena produção, não iria ficar corrigindo 300 ou 400 provas por semestre, sendo ainda encarregado dos trabalhos práticos. O curso só teria sentido se os alunos fossem divididos em turmas para receber um acompanhamento diferenciado. Foi difícil, porém, encontrar aqueles que aceitavam trabalhar como assistentes. Cada um queria dar seu próprio 
curso e pronto, sem levar em conta que docência é uma técnica que se aprende. Pouco importava a formação dos alunos. Um energúmeno leu no primeiro semestre do primeiro ano todo o prefácio da Fenomenologia do espírito, um texto que se torna ininteligível fora do contexto do idealismo alemão.

Essa dispersão não acontece em geral quando se trabalha em laboratório, mas creio que essa irresponsabilidade em relação à docência integrada é em parte uma causa da decadência dos departamentos humanistas. Não estou fazendo propaganda de uma estrutura autoritária, mas, em contrapartida, sou inteiramente contra o individualismo docente. Não vejo como um departamento possa funcionar sem um planejamento comum e alguma hierarquia, obviamente consentida.

Lutamos pela criação de departamentos, e foi nessa luta que a Universidade rachou. Em 1968, chegou a nossa vez. Dos 72 professores indicados (não sei precisar esse número, mas me lembro muito bem que a seleção foi feita por professores da própria USP), apenas 28 foram aposentados. A lista resultava de uma luta interna que começara antes de 1964. A Universidade de São Paulo tinha dois pólos de poder: Direito até metade da Medicina e da Faculdade de Filosofia, Ciências e Letras até o centro, onde a Medicina se colocava partida ao meio. Por isso, já sofrera intervenção em 1964 e agora foi preciso aposentar o novo reitor, Hélio Lourenço de Oliveira. Luís Antonio da Gama e Silva, antigo reitor, tinha sido derrotado, mas não perdeu a chance de se vingar quando assumiu postos importantes no Regime Militar.

Logos depois de 1964, os militares abriram uma sindicância na universidade; no entanto, os tenentes não se saíam bem no confronto com os professores. 
Lembro-me de que nosso professor de filosofia, ao prestar depoimento, foi convidado a cantar o hino nacional - para eles, critério de patriotismo. O diálogo foi mais ou menos assim: "professor, o sr. sabe cantar o hino nacional?". Cruz Costa responde: "sei sim, mas só com música; o sr. assobia e eu canto". Cada professor respondia a seu jeito. Florestan Fernandes chegou diante da comissão, leu uma carta explicando por que se recusava a responder e saiu preso.

Em 1969, a escolha foi mais profissional. Depois do expurgo só me restava emigrar, o que causava problemas com minha esposa, Lupe Cotrim Garaude, que, como poeta, não queria ficar longe da língua portuguesa. Um dia, conversando com Fernando Henrique [Cardoso], me disse ele ser possível permanecer no Brasil. Já se exilara em 1964 e não queria repetir a experiência. Manteve contato com a Fundação Ford, primeiro com o [William] Carmichael, o responsável dela no Brasil, e depois com Peter Bell, seu superior em Nova York, cujo trabalho admirável na América do Sul sempre precisa ser lembrado. Impunha-se como tarefa evitar a drenagem de cérebros durante o Regime Militar, evitar particularmente o desastre ocorrido na Argentina. Foi assim no Brasil e no Chile. Não é à toa que teve problemas com a diplomacia americana.

Foram propostos naquele momento três institutos: um em São Paulo, outro no Rio Grande do Sul e outro em Minas. O único que medrou foi o Cebrap, e acredito que isso ocorreu porque nós já formávamos um grupo em torno daquilo que ficou sendo chamado o "Seminário do Capital". Ao voltar da Europa, em 1958, nós começamos a ler O Capital por inteiro, passamos para Keynes, e quando estávamos lendo Hilferding, veio a repressão e a diáspora. 
Os aposentados do grupo deram coesão a outros aposentados (Elza Berquó, por exemplo), assim como a professores que continuaram na universidade (Candido Procopio Ferreira de Camargo, Fernando Novais etc.). Cabe ainda lembrar que o Cebrap começou dando bolsas aos aposentados cujo perfil não era considerado adequado ao grupo que se formava. Assim, receberam as primeiras bolsas JeanClaude Bernardet e eu mesmo. Embora tivesse assinado sua ata de fundação, ainda não participava do centro do poder. Logo de início houve tentativas de integração quando, por exemplo, Elza Berquó passou a dar aulas de estatística, todos nós com caderninhos em punho. Entretanto, não se pode esquecer de que a situação política nos obrigou a ter uma unidade de ação e ideológica que foi muito importante.

Nesse momento, o Cebrap, assim como o Colégio do México, formávamos dois centros que procuravam entender o que estava acontecendo na América Latina. O auxílio da Ford era decrescente e deveria terminar em dez anos, o que nos obrigava a procurar recursos em outras fundações ou prestar serviços a instituições brasileiras. No fim do período, como a Ford estava contente com nosso trabalho, recebemos um endowment, sendo nossa obrigação também colaborar para um fundo que ajudaria a nos trazer autonomia financeira. Convém lembrar que o Colégio do México e o Instituto Torcuato Di Tella, mais jovem do que o Cebrap, também receberam o mesmo benefício.

Além de recolher os aposentados compulsoriamente, pretendíamos ainda manter um bom relacionamento com a América Latina, o qual tinha se iniciado nos anos setenta. Até mesmo em filosofia mantínhamos contato com Buenos Aires, Córdoba e o México, além, obviamente, do contato mais 
íntimo dos cientistas sociais com todo o continente. A repressão, porém, nos isola, embora nossas publicações tivessem um enorme impacto. Lembro de [Guillermo] O'Donnell dizendo que as esperavam ansiosamente, sendo um dos pontos de resistência intelectual às forças dominantes.

Em 1976, a repressão aumentou, principalmente depois da publicação do livro São Paulo 1975, crescimento e pobreza, de Vinícius [Caldeira Brant]. Na rua Bahia, recebemos uma bomba e fomos obrigados a nos mudar; mas antes cada um precisou sair do Cebrap carregando uma fita no bolso. [Francisco Corrêa] Weffort e [José Álvaro] Moisés tinham gravado entrevistas com líderes sindicais. Imagine se isso caísse nas mãos da polícia! Foi decidido levar esse material provisoriamente para a USP; lá, estaria mais seguro. Acho que está aí uma das sementes do Cedec, pois, naquele momento, era preciso nos dividir.

Veio a anistia. O que fazer? Lembro que um dia fui negociar um projeto com a Martha Muse, da Tinker Foundation, e ela perguntou: "mas qual é a finalidade do Cebrap agora?". Então me ofereceu um grande projeto desde que tentássemos elaborar algo que mudasse a cara do Cebrap. Isso obviamente nunca foi feito. Desde o início, alguns tinham maior participação político-partidária, como Fernando Henrique, Chico de Oliveira, Vinícius etc. Alguns de nós fundamos o PT. A anistia veio em 1980, quando me preparava para ir aos Estados Unidos, para um estágio na Universidade de Columbia. Voltei dois anos depois e fui convocado pelos meus colegas, que me propuseram ficar na direção do Cebrap, aceitando assim meu projeto de transformá-lo num pequeno grupo de estudos avançados. Alguns deles mergulhariam na política. E assim fiquei 11 anos à frente do instituto. 
A idéia era contrabalançar a burocratização dos departamentos com instituições extremamente lábeis que pudessem manter um diálogo interno. Tínhamos prática disso, pois, desde logo, nos reuníamos em torno de uma mesa, o "mesão", para discutir nossos trabalhos. Muitas vezes, havia um diálogo violento, xingávamos uns aos outros, mas depois íamos juntos tomar chopp, pois a amizade estava fora de questão. Isso, de certo modo, atrasou a integração das novas gerações, não acostumadas a essa violência verbal.

Nessa segunda fase do Cebrap, diminui seu caráter mais político e tentou se transformar num instituto onde novos problemas pudessem ser levantados. Muita coisa foi feita e eu me transformei numa espécie de vigilante epistemológico, enchendo o pessoal para formular mais apuradamente as questões. $\mathrm{O}$ dinheiro, porém, era pouco; era preciso correr atrás de projetos, principalmente porque, depois da anistia, o Brasil deixara de ser prioridade das instituições financeiras e precisávamos de recursos locais.

Havia também outra dificuldade: com a anistia, a universidade se abriu; começou a discutir seu próprio projeto, mas cada vez mais sob a pressão sindical - regime único de servidor, salários inteiramente uniformizados, direção paritária e assim por diante -, até que finalmente a Adusp se filiou à CUT, deixando de lado as peculiaridades do projeto de uma universidade. Até na gestão de Ernest Hamburger, do qual eu era o vice-presidente, tentamos manter uma barreira a esse processo de ideologização e homogeneização, mas perdemos. A idéia de se ter um modelo único para todas as universidades brasileiras é maluca; não podemos imaginar universidades com a mesma estrutura levando em conta a diversidade do país. Nunca acreditei que uma universidade precisasse ter sem- 
pre integrados a pesquisa, o ensino e a extensão. A Universidade do Acre nunca poderá ter a USP como modelo, mas pode vir a ser um centro de estudos sobre a Amazônia, base de preparação dos professores do ensino médio e ainda qualificar pesquisadores que farão pesquisa em outros institutos. Os grandes laboratórios, que são raros, como os de Física, precisam ser estrategicamente distribuídos.

Outra questão: a paridade dos salários. Quando integrava a comissão criada por [José] Sarney para estudar a reforma universitária, descobri que um professor do Acre ganhava muito mais do que um professor da Universidade de São Paulo. Achei um escândalo! Mais tarde, fui visitar a universidade de lá: já a encontro em greve, os funcionários reivindicando 30 horas de serviço por semana, o que duplicaria seu número. Depois, fui ao mercado, o que sempre faço ao visitar uma cidade nova; os preços, fora os produtos locais que são poucos, são muito maiores do que os de São Paulo. A conclusão é óbvia: um bom professor só vai lá se ganhar bem e tiver perspectiva de carreira. Não é à toa que encontrei apenas um doutor.

Para nós, a experiência do Programa de Formação de Quadros do Cebrap foi muito importante. Há vinte anos, com o apoio da Capes e do CNPq, começamos a trazer anualmente quatro mestrandos para ficar dois anos no Cebrap, de sorte que tínhamos sempre oito estudantes. A idéia era criar um foco de formação de elite que compensasse a massificação da universidade. Dizia eu: "Vocês chegam aqui e vão utilizar seu ócio para estudar juntos o que quiserem". "Vai atrasar o mestrado?". "Vai, mas terão uma formação que terminará lhes dando a oportunidade de uma carreira muito melhor; depois vocês se recuperam". O sistema 
até hoje é o seguinte: os estudantes se reúnem, montam o programa de acordo com o que lhes interessa: de sociologia à literatura grega ou princípios da física contemporânea. Eu me reservo o direito de equilibrar o curso para que várias áreas sejam cobertas. Uma boa parte dos atuais membros do Cebrap fez o programa. $\mathrm{Na}$ festa em que comemoramos seus 20, dos 91 formados, pelo menos 40 estavam nas universidades ou em postos importantes do Governo. Agora, quando boa parte dos bons estudantes vai diretamente para o doutoramento, ficou difícil fazer uma boa seleção só com mestrandos. Depois de muito hesitar, decidimos recrutar doutores recentes, mas ainda estamos experimentando. Até agora tem sido triste, pois recebemos projetos que não poderiam ser tomados como textos de alunos de graduação. A qualidade em geral é muito baixa, mas, pelo menos, os doutores que temos selecionado quase todos entram numa universidade antes de terminar o programa. Se isso mostra a qualidade da seleção, cria problemas para o ritmo dos estudos.

Aqui está, a meu ver, uma nova função para nossas instituições. O Cebrap funcionou como escola de formação de quadros, sem deixar a pesquisa obviamente. Daí uma dialética possível com a universidade. Muitas vezes é importante examinar o que está sendo feito na universidade e fazer o contrário. Diante da massificação do ensino universitário, torna-se vital criar mecanismos de formação de elites. Até agora, o sistema de avaliação é muito fraco e, particularmente, as faculdades de filosofia, letras e ciências humanas continuam a ser afetadas pelas ondas ideológicas vindas de fora. Disso tudo resulta uma pasta informe.

Quando cheguei à Faculdade, o marxismo era a ideologia dominante, principalmente o marxismo da Terceira Internacional. No fim dos anos 1950, Sartre 
foi até mesmo entronizado como o horizonte de nosso pensamento. Eu mesmo passei anos tentando mostrar que os textos de Marx são muito mais sofisticados do que a Vulgata; permitem uma grande diversidade de leituras. De repente, veio a onda de Althusser, que transformou o marxismo num estruturalismo, o que permitiu uma enxurrada de estruturas regionais, modos de produção para todos os lados. Finalmente saiu da moda, dando lugar a outros. Menciono isso para mostrar como há uma tendência de nossos estudos de não acumularem resultados.

Convém ainda lembrar que a estrutura da universidade está em crise no mundo todo, de sorte que, como muitas vezes, temos de criar instituições que já começaram a balançar. Daí a enorme importância, para todo o sistema universitário, de desenvolver uma política de alianças com outros institutos de pesquisa, com universidades estrangeiras e com redes de pesquisa tecnológica. Em geral, a universidade cuida das ciências básicas, mas as inovações provêm de institutos, como a Embrapa, onde se faz essa mistura de ciência e tecnologia que caracteriza o saber contemporâneo.

Com o passar do tempo, novos grupos se formam no Cebrap, no Cedec, que terminam naturalmente assumindo o poder, alterando o rumo do próprio instituto. Na universidade, essa passagem de gerações tem menos saltos, mas está sempre ameaçada pelo fantasma da gestão paritária, cujos efeitos perversos nem vale a pena mencionar. O mais importante é que o centro de poder tende para o lado dos funcionários e dos alunos, o que emperra novas experiências. Nem todas as instituições podem ter gestões democráticas, no sentido formal que hoje atribuímos à democracia; isso para garantir precisamente que a democracia venha a ser uma forma de vida. 
Gabriel Cohn: Há exatos dez anos, na Filosofia, Istvan Jancsó organizou um simpósio "Humanidades, Pesquisa, Universidade", com a participação de vários colegas nossos, e convidaram Francisco de Oliveira para falar sobre a pesquisa fora da universidade. É interessante o texto dele, porque faz um levantamento meticuloso, pegando os relatórios dos centros e discutindo o que se fazia fora da universidade. Enfatiza muito o caráter inovador, a busca de temas não triviais, a fecundação recíproca das atividades, a interdisciplinaridade etc. Mas ele não estava, naquele momento, preocupado com a questão que foi colocada aqui para nós, ou seja: o que isso tem a ver com o empenho pela democracia, ou a busca de algum grande tema diretor. Pelo contrário, ele enfatiza a diversidade, mostrando como esses centros - e este, aliás, é um ponto importante na sua argumentação - dialogam de maneira muito fecunda com a universidade. Isso em 1996, quando já estava bem avançado esse processo todo. Ele não estava preocupado em mostrar uma espécie de diretriz que estivesse presente nas atividades desses centros.

Se olharmos a proposta de hoje, está sugerida uma diretriz e está sugerida uma natureza desses centros que, creio, têm de ser colocadas aqui em nosso debate, porque estamos falando da contribuição dos centros independentes para a democracia. Aqui não se pode embaralhar as coisas. Primeiro, a questão dos centros independentes. Quando Francisco de Oliveira falava sobre os centros, o tema era neutro: os que estão fora da universidade. Claro que ele mostra a maneira pela qual foram constituídos e em que condições, mas eles estão fora. Então, ele está falando de dentro da universidade nesse momento, embora, claramente, tivesse 
também mobilizado sua experiência no Cebrap, e está preocupado com o intercâmbio entre os que estão trabalhando fora e os daqui. Esse, porém, é um problema neutro. Agora, se você fala "independente", a coisa complica, porque se coloca a questão: em relação a quê você é independente? Como você exerce essa independência? A questão original não era ser independente da universidade, era ser independente dos centros de poder nacional que estavam sufocando a universidade. Tratava-se de encontrar um espaço em que se pudesse pensar de maneira mais oxigenada. Naquele momento, a questão era decisiva; no momento da fundação, nos primeiros anos, independência e empenho na questão democrática eram inseparáveis. Afinal de contas, marcava a sua independência o pensar aquilo que, de frente, contestava o regime.

244 Se você pensa isso agora, a questão da independência coloca-se de maneira altamente problemática. Mesmo naquele tempo - estou convencido disso, e acho que essa é uma questão que merece ser retomada aqui -, essa independência nunca foi tranqüila; foi sempre um problema. Sempre se tratou de descobrir o modo pelo qual nós podemos discutir, pensar e publicar, que tenha a marca da independência. A mim me preocupa, por exemplo, o modo pelo qual a questão da democracia acabou sendo introduzida, porque nós incorporamos aqui uma problemática - que, aliás, era cara aos centros internacionais que nos financiavam - que passava pela questão da sociedade civil, pela questão da cidadania, mas, sobretudo, pela questão da sociedade civil, que era um grande tema internacional, produzido em condições muito peculiares na Europa comunista, na Europa do Leste, na Polônia, na Hungria, e 
que encontrava ressonância imediata nos centros de pensamento ocidentais, naqueles que estavam empenhados em financiar a pesquisa. Os centros que se constituíam tinham de encontrar algum ângulo para pensar a questão da democracia, da construção de uma ordem democrática, da resistência à ditadura, e esse ângulo, em princípio, dava-se por esses conceitos, que, no entanto, saíam de um outro tipo de luta, contra um outro tipo de regime, autocrático, despótico, como quer que o chamemos.

Tenho para mim que, ao longo do desenvolvimento dessas discussões, nas quais se envolvem o Cebrap, o Cedec - o Iuperj é um caso à parte, e eu só lembro porque Chico Oliveira o cita -, mas pensem nesses dois grandes irmãos aqui de São Paulo. Tenho a forte impressão de que foi possível fazer uma inflexão e introduzir um ângulo pelo qual se possa reivindicar uma independência intelectual, numa certa medida difícil, eu diria problemática, e eu me pergunto se, em alguns momentos, todos, o pessoal de dentro dos centros, o pessoal de dentro da universidade, afundaram um pouco numa problemática que, de certa maneira, eu me arriscaria a dizer, foi induzida pelas grandes fundações americanas que apostavam nesse tipo de coisa e na qual, no entanto, foi possível colocar algum viés. Por exemplo, aqui no Cedec, a ênfase na questão do público, que alguns à época - e acredito que até hoje - percebiam pelo lado de uma certa simpatia republicana, mas que permitia ancorar melhor essas questões nos problemas de uma sociedade em que essa dimensão era historicamente muito problemática. Houve, creio eu, ainda que não de modo explícito, uma percepção de que independência era algo a ser buscado, constantemente bus- 
cado. Porque não era o fato de você ter saído da universidade e você estar na luta contra a ditadura que lhe dava automaticamente independência. Você poderia ter engolido, com anzol e tudo, uma problemática que veio induzida - e eu uso o termo brutal - pelas grandes fundações que financiavam isso aqui e que tinham suas concepções, que tinham sua inserção muito específica naquela fase final da Guerra Fria etc.; não era só o empenho democrático que estava ali.

O meu palpite é que se conseguiu, na dimensão intelectual, introduzir uma forma de pensar essas coisas que, por vários ângulos, permitia dar um certo conteúdo a essa condição independente que, no meu entender, continua sendo e é cada vez mais problemática. Hoje, como é que se define a independência desses centros? Como você os relaciona com as instituições que aí se recuperam e se expandem novamente, como a universidade, mantendo algo que se possa chamar independência? Qual é o modo intelectual de se definir essa independência? Eu já nem vou falar da luta pelo dinheiro daqueles que estiveram aqui na direção do Cedec, da luta para mantê-lo, conseguir fundos, e, ainda assim, não submergir diante de exigências que transformariam essas instituições em algo muito próximo a pequenas empresas de pesquisa. A marca nunca foi essa.

Eu não dou, sem mais, o caráter independente dos nossos centros como assegurado. Isso foi conquistado a duras penas, e, às vezes, de maneira espontânea, porque não era uma questão de "vamos por esse ângulo, porque queremos criar um enfoque intelectual, científico, de reflexão que seja nosso e não do resto”. É porque, isso sim, 
desenvolveu-se nesses centros uma especial sensibilidade às questões emergentes na sociedade. Isso ganha uma marca - boa. Não paramos. Não paramos em 1975, 1976, 1980, ainda que tenha havido uma dessensibilização forte. A escala da coisa, a diversidade dela, o debate contínuo e intenso, tudo isso certamente ajudou. Nesse ponto, não é irrelevante o fato de que uma instituição, que tem de lutar cotidianamente pela sua mais elementar sobrevivência, desde os fundos para se manter até a defesa contra pressões externas de todo tipo, obriga-se a ser muito esperta. Ela leva vantagem em relação aos paquidérmicos, a instituições como a universidade - que não acho que tenha sido tão estéril nesse período todo; é uma vantagem enorme estar num centro como este.

Agora, eu acompanharia entusiasticamente a provocação do Giannotti de que, nesse momento, problematizar é a questão. E sermos conscientes de que nós vivemos isso e vivemos aquilo. É problemática a nossa capacidade de refletir por nossa conta, é problemática a nossa independência em relação ao entorno, a nossa independência em relação a quem nos mantém, tudo isso é altamente problemático. Mas o que foi o bom desses centros? Transformar essa sua condição problemática... embutir essa condição problemática na sua própria reflexão. O que nós estamos acompanhando, na realidade, e todo mundo está cansado de sofrer isso, é uma erosão, ao longo dos anos, dos grandes temas que preocuparam o Cebrap e o Cedec. A questão da democracia... bom, mas democracia é uma palavra erodida da maneira mais brutal, cidadania é erodida da maneira mais brutal, república, público, o que vocês quiserem; a erosão é brutal, muito perto de 
ser slogans. Não estou dizendo nenhuma novidade; isso faz parte do cotidiano de todos nós; estou só tentando verbalizar. A questão é conseguir recuperar tudo isso pela via crítica; com mais força do que em qualquer outro momento, introduzir essa reflexão como componente crítico donosso trabalho. Do contrário, estaremos sim engolindo algo que teve em algum momento a dignidade de um conceito e que agora é uma palavra vazia, uma fórmula vazia. Se não for possível fazer esse tipo de recuperação crítica, de fato o nosso trabalho fica pesadamente comprometido. Não dá para colocarmos o tema desta mesa, neste momento, sem nos perguntarmos duramente sobre o que significa qualificar um centro como o Cedec - que no caso está em jogo, nos seus 30 anos - como independente. O que significa isso? Foi dificílimo em alguns momentos assegurar isso; agora, em que tudo é mais manso e que é fácil você entrar na deriva, porque não estamos sendo fustigados por uma ditadura, o que significa independência? Sobretudo, o que significa contribuir para a democracia, para o processo democrático, se nós não tivermos uma impiedosamente crítica e reflexiva concepção do que venha a ser o tal processo democrático?

Nesse ponto, estou retomando uma provocação que, a meu ver, é absolutamente vital: eu tremo de pensar que possamos aceitar, sem mais reflexão, a definição de que somos independentes. Não sei se somos. E tremo de pensar que estejamos construindo uma coisa que ficou... uma geléia. O que é? Por qual ângulo? Como é que vamos fazer isso? É uma espécie de maldição você ser o primeiro centro, você fica ali... toda a água da chuva cai ali naquele telhado. Portanto, eu coloco enormes pontos 
de interrogação e de dúvida sobre o nosso próprio tema: independente e democrático.

Mas gostaria de pegar isso por outro ângulo de observação. Isso obviamente não aconteceu por dificuldade de reflexão, de pesquisa etc., mas deixemme fazer uma observação aqui que me atormenta há séculos e me atormentou especialmente quando houve a fase da recuperação, da redemocratização, da constituição de novos partidos. Creio que nossos centros terão feito uma enorme contribuição uma vez que tenham saído fora daquilo que eu consideraria um dos piores efeitos da ditadura, que foi corromper o pensamento de esquerda, no sentido de que criou os consensos fáceis. Numa certa época, quando se começou a avançar no processo de redemocratização, em meados dos anos 1980, em que os consensos fáceis predominavam, todos eram democratas, todos votavam pela democracia, todos estavam contra o autoritarismo etc. e, com isso, tinha-se álibi para qualquer tipo de pensamento, para qualquer tipo de ação. Se os centros conseguiram sair fora do chamado consenso fácil e continuaram seu trabalho de formiguinha, de se questionar, isso já é uma imensa contribuição. E não é que tenha sido uma contribuição ao manter à distância os inimigos da democracia; é uma contribuição no sentido de, numa certa maneira e indiretamente, puxar as orelhas dos amigos apressados da democracia, que estavam simplesmente a usando como álibi, e então: "vamos fazer tal coisa democraticamente"; era esse o papo naquela época. E se os centros fizeram isso, já fizeram muito, porque a democracia é uma coisa que tem de ser defendida dos seus amigos, para usar uma frase utilizada em outros contextos, porque os inimigos, esses nós sabemos que é possível mantê-los a distância. 


\section{José Arthur Giannotti}

é professor emérito do Departamento de Filosofia da FFLCH-USP e pesquisador do Cebrap

\section{Gabriel Cohn}

é professor do Departamento de Ciência Política da FFLCH-USP e ex-editor da revista Lua Nova 


\section{AS INSTITUIÇÕES DE PESQUISA INDEPENDENTES E A QUESTÃO DEMOCRÁTICA}

José Arthur Giannotti e Gabriel Cohn, os expositores do segundo seminário, conversam sobre o contexto especificamente acadêmico que deu impulso às brilhantes trajetórias de instituições como o Cedec e o Cebrap (Centro Brasileiro de Análise e Planejamento) e em que sentido elas ingressaram mais recentemente em novo contexto, impondo-lhes novos desafios. 
Palavras-chave: Instituições de pesquisa independentes; Democracia; Brasil; Cedec; Cebrap.

\section{THE INDEPENDENT RESEARCH INSTITUTES AND THE DEMIOCRATIC QUESTION}

José Arthur Giannotti and Gabriel Cohn, the speakers of the second seminar, talk about the particular academic context which gave impulse to the outstanding performances of institutions like Cedec and Cebrap (the Brazilian Centre for Analysis and Planning), and in what sense they have recently entered a new context, with new challenges.

Keywords: Independent research institutes; Democracy; Brazil; Cedec; Cebrap. 